\title{
D-InSAR Analysis of Sentinel-1 Data for Landslide Detection in Northern Morocco, Case Study: Chefchaouen
}

\author{
Azizi Bouchra, Hakdaoui Mustapha, Raji Mohammed \\ Laboratory of Applied Geology, Geomatics and Environment, Hassan II University of Casablanca, Faculty of Sciences Ben M'sik, \\ Casablanca, Morocco \\ Email: azizibouchra13@gmail.com
}

How to cite this paper: Bouchra, A., Mustapha, H., \& Mohammed, R. (2020). D-InSAR Analysis of Sentinel-1 Data for Landslide Detection in Northern Morocco, Case Study: Chefchaouen. Journal of Geoscience and Environment Protection, 8, 84-103. https://doi.org/10.4236/gep.2020.87005

Received: June 8, 2020

Accepted: July 21, 2020

Published: July 24, 2020

Copyright $\odot 2020$ by author(s) and Scientific Research Publishing Inc. This work is licensed under the Creative Commons Attribution International License (CC BY 4.0).

http://creativecommons.org/licenses/by/4.0/

\begin{abstract}
Land surface displacement caused by landslides is among the most damaging phenomena in northern Morocco. In this paper, we measure ground deformation in the Chefchaouen area which is a zone characterized by geological formations and structurally complex losses that promote instability (landslide, mudflow, block falls, etc.) leading to slow to extremely slow deformation phenomena, which require an interferometric study, using the DinSAR (differential interferometric synthetic Aperture Radar) technique with sentinel 1 images in bance $\mathrm{C}$, which is a powerful tool for the detection and analysis of interferences and monitoring of ground deformations. We worked on four areas of the study area. Its points are provided by the direction of the roads, which generates Interferograms and then deformation maps with precision in $\mathrm{mm} /$ year.
\end{abstract}

\section{Keywords}

Landslides, Slopes, SAR, DInSAR, Interferometric, Synthetic Aperture Radar, Sentinel 1

\section{Introduction}

Landslides are among the geological hazards that are responsible for enormous human and natural losses (Lorenzo et al., 2020). The mountainous regions of Northern Morocco are characterized by high winter precipitation, responsible for a significant evolution of the slopes with the development of gravitational movements (GM), such as landslides, debris flows, collapses and intense gullies or badlands (BL) (Mastere, 2011). 
This paper focuses on landslide detection and mapping using the DInSAR (Interferometric SAR) technique with images from the Sentinel 1 satellite. This Differential interferometric SAR is based on processing two single look complex interferometric wide images (SLC IW). Each pixel of SAR data contains a complex number (amplitude and phase) of the microwave field backscattered, which corresponds to resolution cell, projected on the ground (Ferretti et al., 2000).

DInSAR is a powerful tool for detecting and monitoring ground deformation. It has been widely exploited during the last three decades, allowing significant results in several fields, For instance, successful land deformation estimates have demonstrated the potential of this technique for a wide range of applications related to landslides (Colesanti et al., 2003; Hilley et al., 2004; Bovenga et al., 2012), land subsidence caused by ground wa-ter pumping (Tomás et al., 2005; Stramondo et al., 2007; Bell et al., 2008; Heleno et al., 2011) and mining (Colesanti et al.,2005; Jung et al., 2007), or urban monitoring (Crosetto et al., 2008; Vallone et al., 2008; Cigna \& Tapete, 2012). The aim of this document is to map the landslide points (PK) in Stehat accurately, Talambote, Derdara, Eljebha with accuracies in $\mathrm{mm}$ /year obtained by the Road Directorate of the Chefchaouen region and to establish deformation maps. The objective of this document is to validate the application of the DInSAR processing chain to the monitoring of the slip point (PK) in Stehat, Talambote, Derdara, Eljebha with accuracies in $\mathrm{mm} /$ year obtained by the Road Directorate of the Chefchaouen region, using open access data and free tools of the Copernicus program. In particular, a DInSAR processing chain has been proposed and deformation maps have been elaborated and will be discussed in detail.

\section{Material and Method}

\subsection{Study Area}

According to the historical table of landslides (Table 1), provided by the Road Directorate of Chefchaouen and the laboratory of Studies and Tests, the area that was started in this study is the province of Chefchaouen precisely Eljebha, Derdara, Bab Berred, Stehat and Talambote, These are points limiting the province of Chefchaouen (Figure 1(a)) which is a region located in the centre of the rifaine chain limited in the North by the Mediterranean Sea over a length of 120 $\mathrm{km}$, in the South by the Provinces of Taounate and Sidi Kacem, the East by the Province of Al Hoceima and in the West by the Provinces of Tetouan and Larache with $600 \mathrm{~m}$ (Figure 1 (b)) of altitude, it is characterized by a great diversity of the soil formed by limestone and siliceous layers.

\subsection{Geological Setting of the Study Area}

The Rifaine zone is formed by a geological structuring consisting of quartzite sandstones and dorsal limestones as well as flysch layers. This context is associated with a climate that is both Mediterranean and oceanic, as well as with the active tectonics of over-rection of the Rifaine domain (Figure 2). 


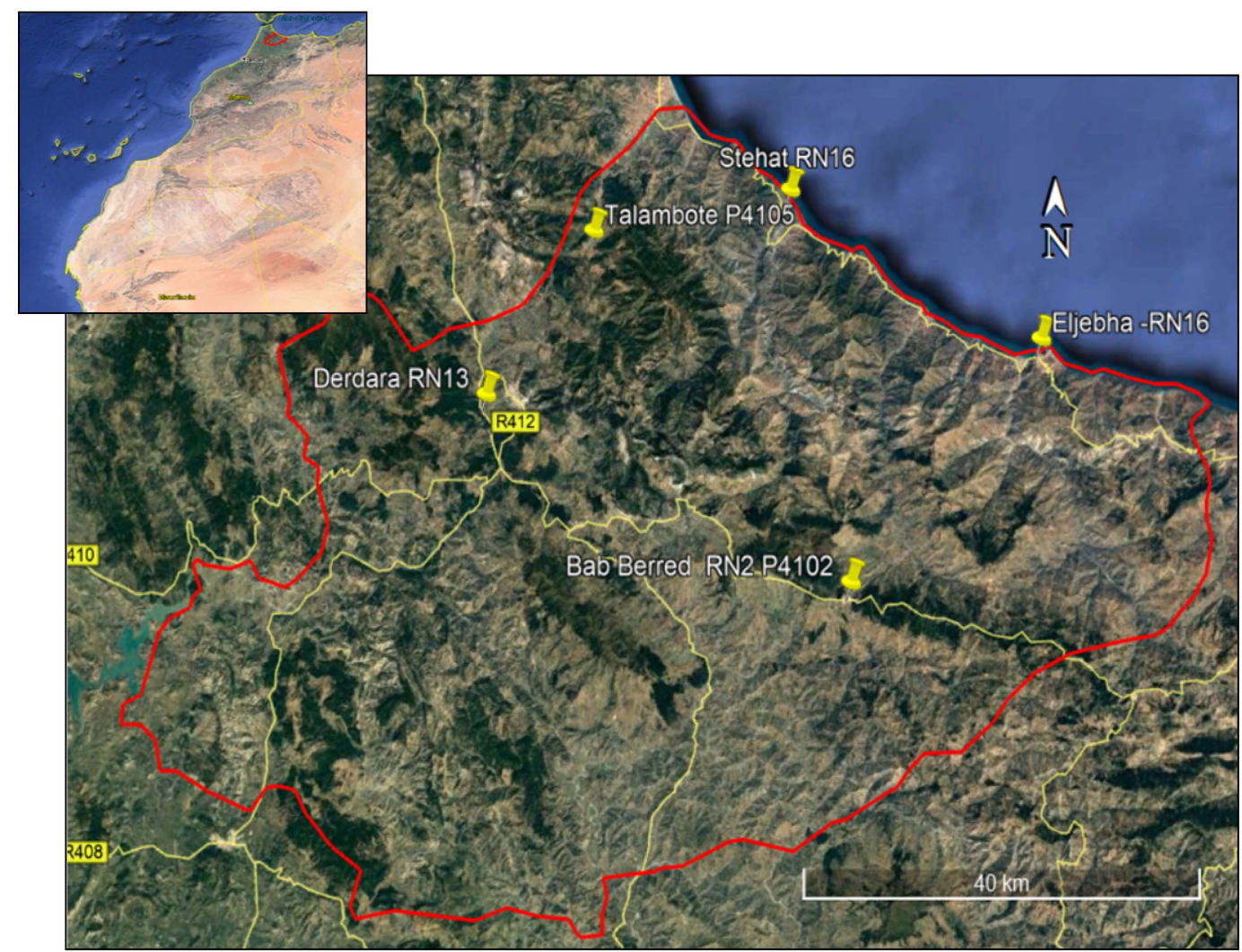

(a)

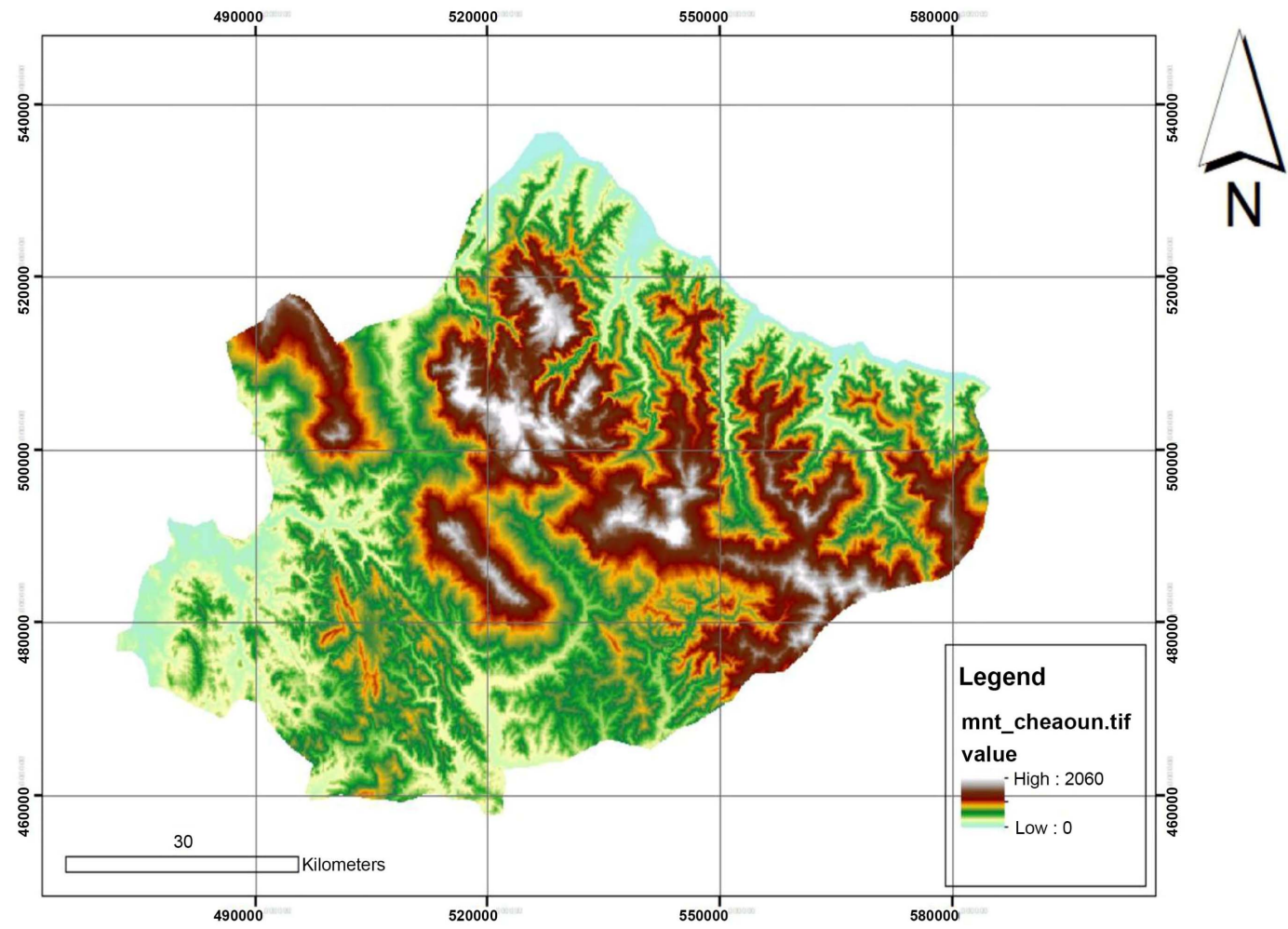

(b)

Figure 1. (a) Location of the study area (P4105, RN16, RN13, P4102) Chefchaouen Province; (b) Digital Elevation Model (DEM) of the study area (P4105, RN16, RN13, P4102) Chefchaouen Province. 
Table 1. Landslide history provided by the Chefchaouen roads directorate.

\begin{tabular}{cccc}
\hline Section & Sliding point PK & The date of the landslide & The causes \\
\hline & PK $13+600$ & $30 / 10 / 2012$ & $\begin{array}{c}\text { The effect of geology, Water and topography } \\
\text { Oued Laou-Province Chefchaoun }\end{array}$ \\
& PK $29+800$ & $30 / 10 / 2012$ & $\begin{array}{c}\text { The terrain in place consists of highly altered shales with a } \\
\text { clay matrix, which are underlain by massive fractured shale. }\end{array}$ \\
& PK $32+900$ & $30 / 10 / 2012$ & Geology, water and topography. \\
Stehat/eljebha Province Chefchaoun & PK 140 & $19 / 07 / 2015$ & Clay soil \\
Bab Berred Province of Chefchaoun & P4102 & $01 / 07 / 2015$ & Clay soil \\
Talambote Province of chefchaouen & PK $168+500$ & $9 / 09 / 2015$ & geology, water and topography \\
Derdara & RN13 & $12 / 09 / 2015$ & geology, water and topography \\
Stehat & PK 158 & PK34 & geology, water and topography
\end{tabular}

1 : sea

2 : foreland

3 : Limestone Backrest

4 : flysch sheets

5 : Sebtides and Ghmarides;

6: Tangier Ketama unit

7 : neo-genic and quaternary

volcanism

8: Méso-Rif ;

9: Pre-Rif

10 : Intra-Rif

11 : Post-tableclothes plots

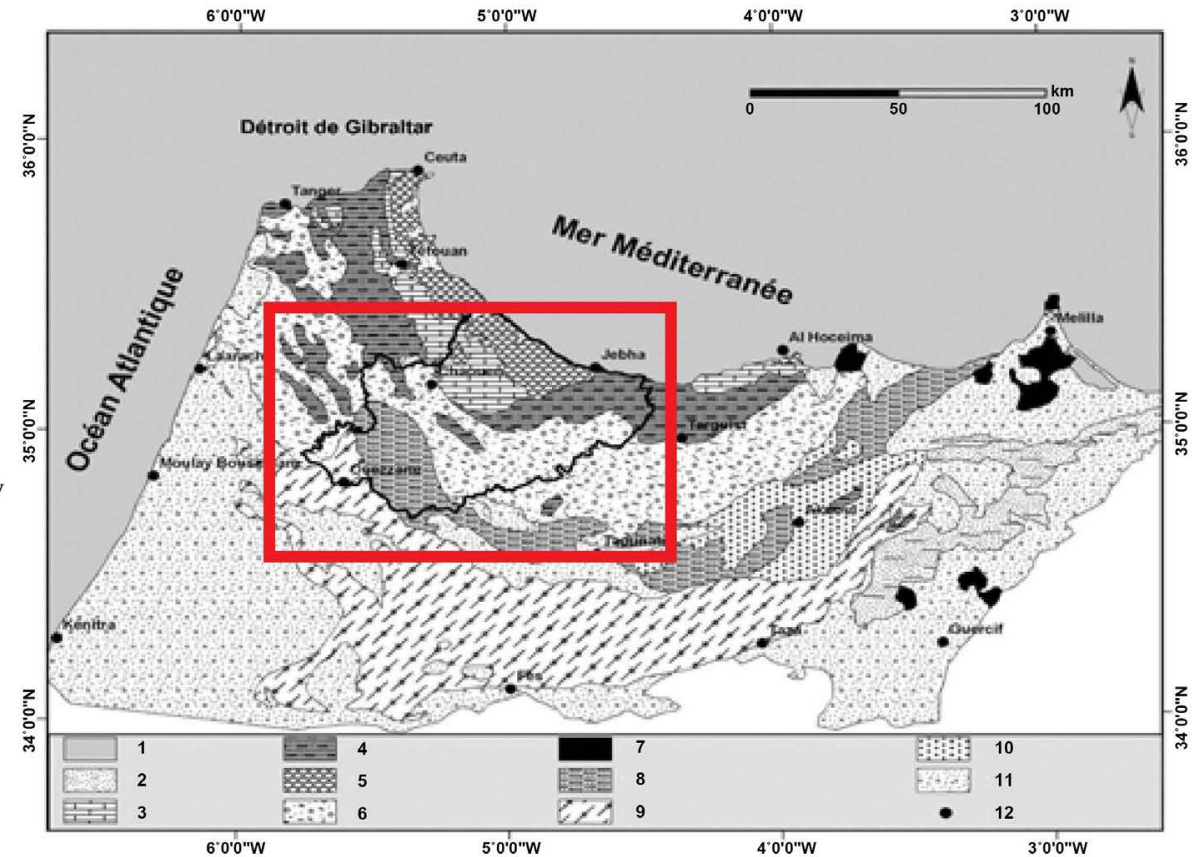

Figure 2. Geological setting of the study area (area framed by the black frame) (Master, 2011).

\subsection{Landslide History of Chefchaouen Province}

According to the "Roads Directorate, Provincial Equipment, Transportation and Logistics Directorate of Chefchaouen". Several landslides affected the study area (Chefchaouen province) during the period analysed (October 2012-June 2017) - see Table 1-in particular on national road 16 (Figures 3(a)-(d)), these landslides are mainly triggered by the nature of the geology and heavy rainfall

\subsection{DATA and Methodology}

DATA: 


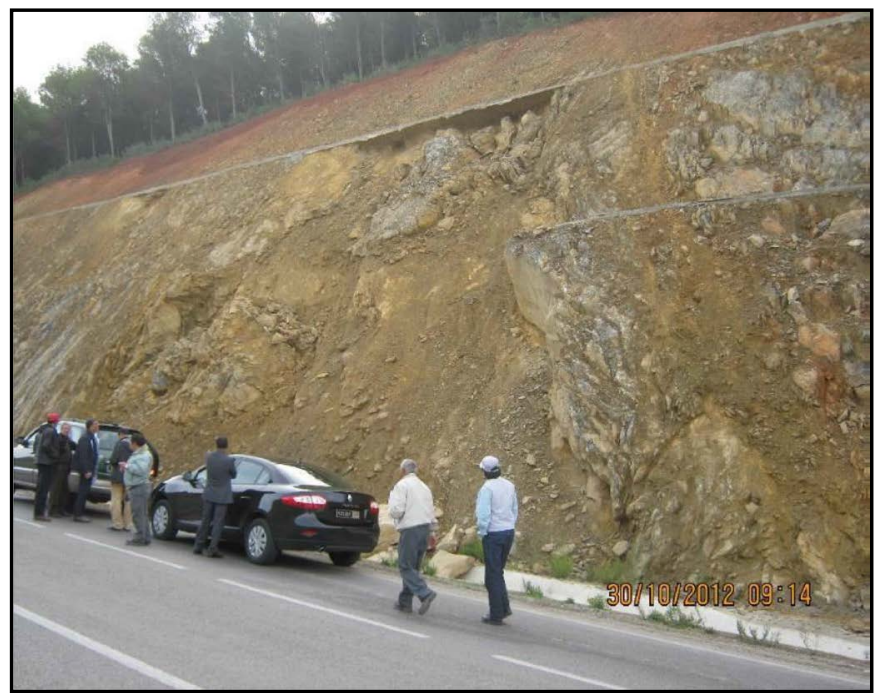

(a)

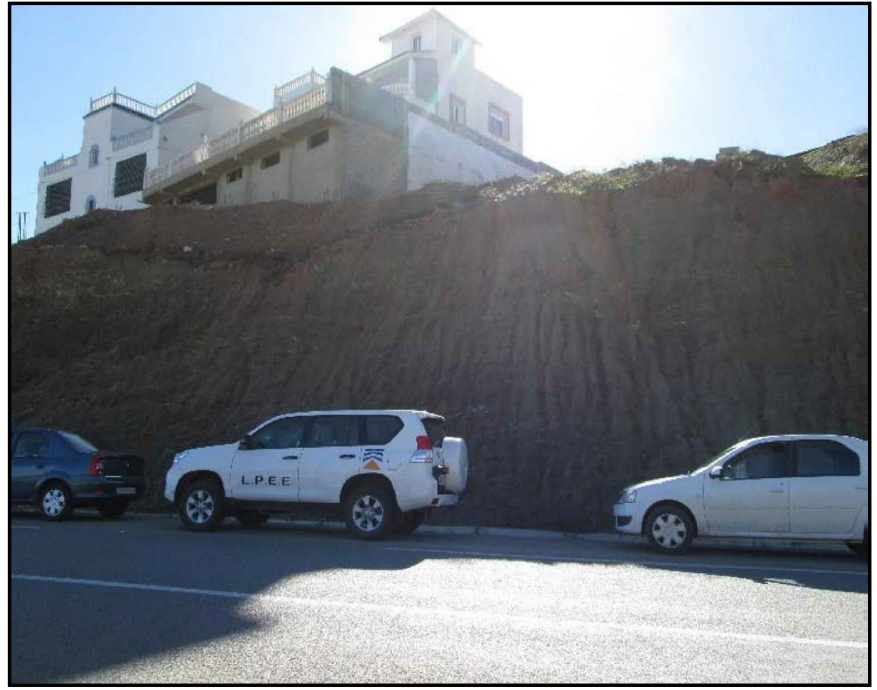

(b)

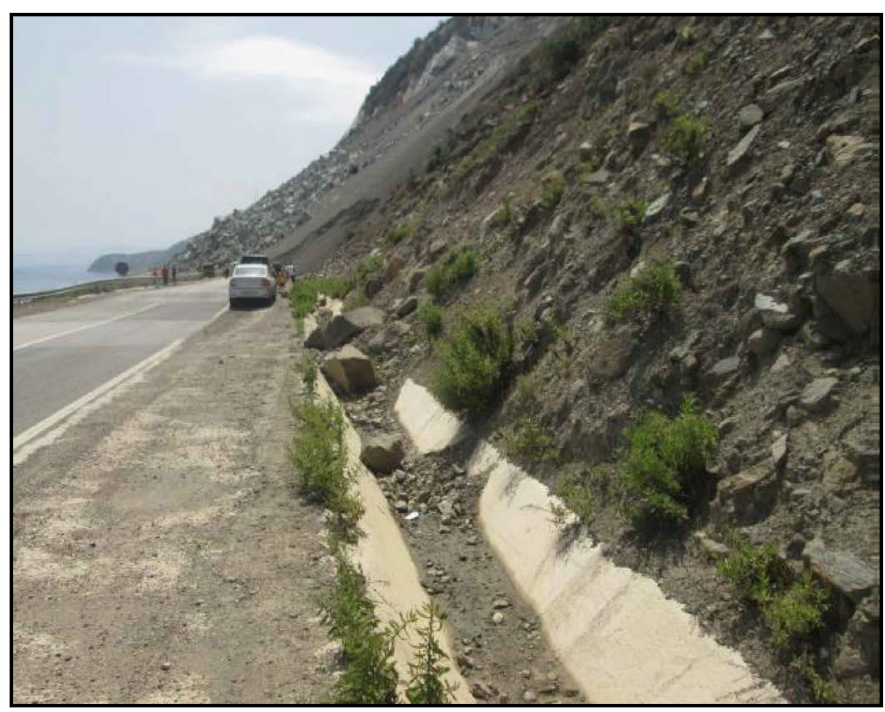

(c) 


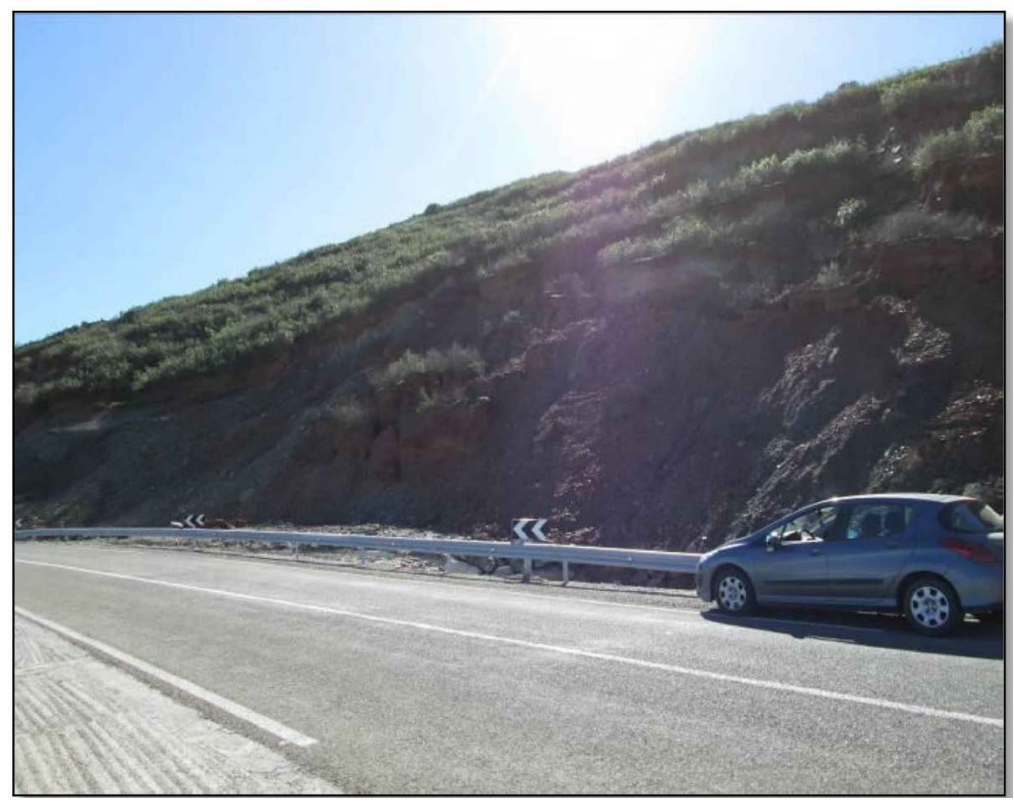

(d)

Figure 3. (a) Landslide on Oued Lou Chefchaouen province; (b) Landslide on Derdara road; (c) landslide on Eljebha road; (d) landslide on Talambote road.

The SAR data used in this study are acquired by the Sentinel1- A sensor and are downloaded free of charge from the Copernicus program. The choice of these data is made on several criteria (satellite mission, type of product, acquisition mode, orbit and polarization) as shown in the following table (Table 2).

We have downloaded the Sentinel-1 images from the Copernicus Open Access Hub in Single Aspect Complex (SLC) level 1 mode, with VV or VV-VH polarizations depending on availability at the various test sites, and Wide Interferometric (IW) acquisition mode. SLC products are based on focused SAR data, geo-referenced using orbit and attitude data from the satellite, and provided in oblique range geometry.

The pairs of Sentinel 1 images were chosen according to the landslides (Table 1) Images before and after the event.

\subsection{Methodology}

Synthetic Aperture Radar (SAR) is a system capable of obtaining complex, high-resolution images from large areas of terrain, usually located on board an orbital or aerial platform, but which can also be used in ground-based deployments (Yerro et al., 2014). D-InSAR, which uses the phase information of 2 SAR images at different times in the same area by satellite-loaded radar sensors and the DEM of this area to monitor surface deformation, is Differential Interferometry Synthetic Aperture Radar monitoring technology (Raucoules et al., 2007; Berardino et al., 2002).

Advanced SAR image processing has proven its ability to detect and map landslides (Farina et al., 2006, Cascini et al., 2009, Guzzetti et al., 2009, the traditional 
Table 2. Sentinel 1 data for interferogram generation.

\begin{tabular}{lllcccccc}
\hline \multirow{2}{*}{ Acquisition } & \multirow{2}{*}{ Mission } & \multicolumn{2}{c}{ Product } & Acquisition & Orbite & Trck & Polarization & Orbit pass \\
& & type & Mode & OW & & & \\
\hline 08 June 2015 & Sentinel 1-A & SLC & IW & 6278 & 81 & VV & DESCENDING \\
26 July 2015 & Sentinel 1-A & SLC & IW & 6978 & 81 & VV & DESCENDING \\
24 August 2015 Sentinel 1-A & SLC & IW & 7401 & 154 & VV & DESCENDING \\
29 July 2015 & Sentinel 1-A & SLC & IW & 7926 & 154 & VV & DESCENDING \\
09 June 2017 & Sentinel 1-A & SLC & IW & 16953 & 81 & VV & DESCENDING \\
21 June 2017 & Sentinel 1-A & SLC & IW & 17128 & 81 & VV & DESCENDING \\
\hline
\end{tabular}

two-pass differential InSAR (D-InSAR) technique has been applied for the monitoring of slow landslides of the order of $\mathrm{cm} \cdot \mathrm{yr}^{-1}$ (Catani et al., 2005).

It provides an image, called a differential interferogram, representing the ground motion between acquisitions with centimetric precision and decametric resolution.

It consists of exploiting the phase information contained in complex SAR imagery recorded by one or more sensors by varying an acquisition parameter (date, position and orientation of the radar, frequency, polarity of the transmitted/received wave) according to the desired application (Bamler \& Hartl, 1998). Is a reliable method for measuring small movements $(1 \mathrm{~cm})$ with high spatial resolution $(10 \mathrm{~m})$ over large areas $\left(50 \mathrm{~km}^{2}\right)$

The interferometric phase between two SAR images includes the following contributions:

$$
\Delta \varnothing=\Delta \varnothing_{\text {flat }}+\Delta \varnothing_{\text {height }}+\Delta \varnothing_{\text {displacement }}+\Delta \varnothing_{\text {atmosphere }}+\Delta \varnothing_{\text {noise }}
$$

Hence $\Delta \varnothing_{\text {flat }}$ is the contribution of the flat earth phase, $\Delta \varnothing_{\text {height }}$ presents the topography, $\Delta \varnothing_{\text {displacement }}$ the part of the phase that represents the ground deformation along the line of sight, $\Delta \varnothing_{\text {atmosphere }}$ the contribution of the phase caused by the delay of wave propagation in the atmosphere and $\Delta \varnothing_{\text {noise }}$ is the residual noise, the D-InSAR technique aims to eliminate all interferometric contributions except for the displacement contribution. After removal of all these components, only the ground deformation component is presented on the interferogram.

In our study we collected the previous landslide points of the study area, we had a total of seven points since 2012. However, since the present study will be done with Sentinel 1 Radar imagery, we took the points since 2015 which makes the total of points to about 6 Sentinel 1 Radar images (Table 3), in our study we used Differential Radar Interferometry to generate differential interferograms as shown in (Figure 4) these interferograms were filtered using the GOLDSTEIN fitting and using the SNAP toolbox software, the phase unpacking was performed with the SNAPHU software, then the displacement was calculated from the unwrapped interferogram, finally the results were georeferenced using the Doppler terrain correction. 
Table 3. Interferometric pairs.

\begin{tabular}{cc}
\hline & Interferometric Pairs \\
\hline 1 & 8 June $2015 \rightarrow$ 26 July 2015 \\
2 & 29 July $2015 \rightarrow$ 24 August 2015 \\
3 & 09 June $2017 \rightarrow$ 21 June 2017 \\
\hline
\end{tabular}

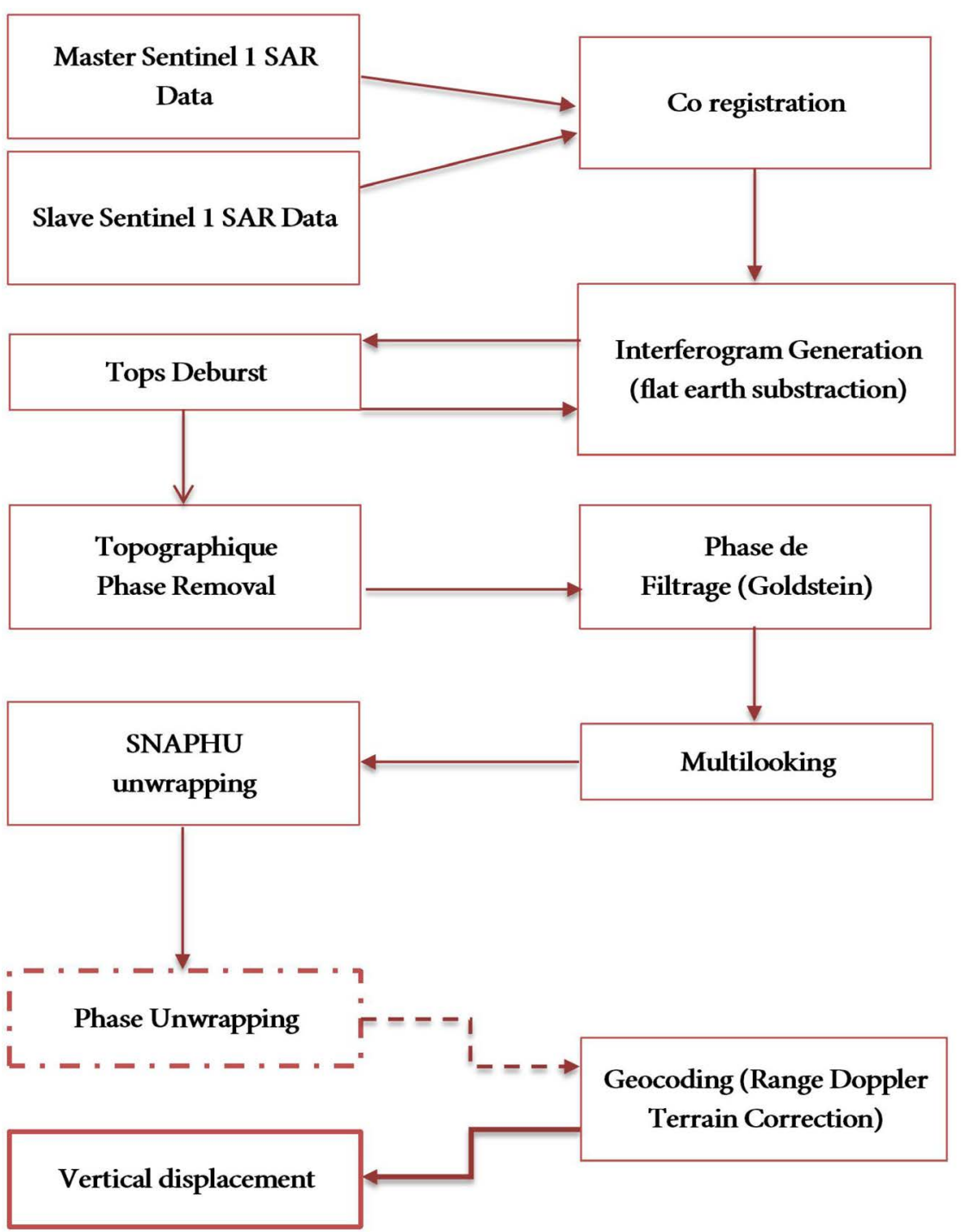

Figure 4. Schéma de la méthodologie D-InSAR.

\section{Result and Discussion}

\subsection{Coherence Image}

After Co-registration the SLC images, coherence map is computed due to the complex correlation coefficient between two acquisitions. It gives the level similarity of pixels between the slave and master images in a scale from 0 to 1 .

The image of coherence of the couple 8 June/26 July 2015 of the point PK140 RN16 around the Eljebha Point and the Bab Berred point is presented in (Figure 
5(a)) the values close to 1 presented in white indicate a strong coherence that means that there is no phase noise while the values close to 0 presented in black indicate a weak coherence that means that there is phase noise, The high elevation of the zone is focused on the eastern part of the zone, Eljebha (Figure 5(b)), while that of the Bab berred zone (Figure $5(\mathrm{~b})$ ), is focused on the southern part of the zone.

Figure 6(a) presents the coherence image of the pair 9 June and 21 July 2017 in descending orbit with a time baseline of 41 days over the area of interest presented by yellow pointers (Stehat and Talamobte), it is noted that it is a medium coherence image revealing globally medium to high levels of coherence over the entire area of interest. The coherence is almost high in the coherence image covering the date from 29 June to 24 August 2015 (Figure 7(a)), low to medium in the Talambote zone, and high to very high in the Derdara zone (Figure $7(\mathrm{~b})$ ).

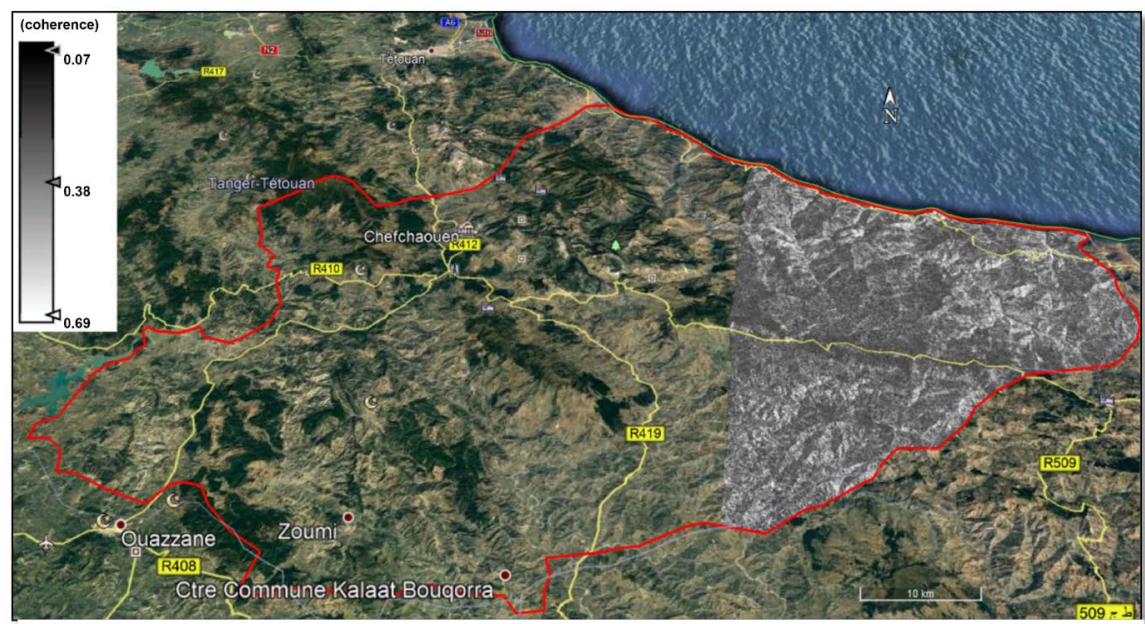

(a)

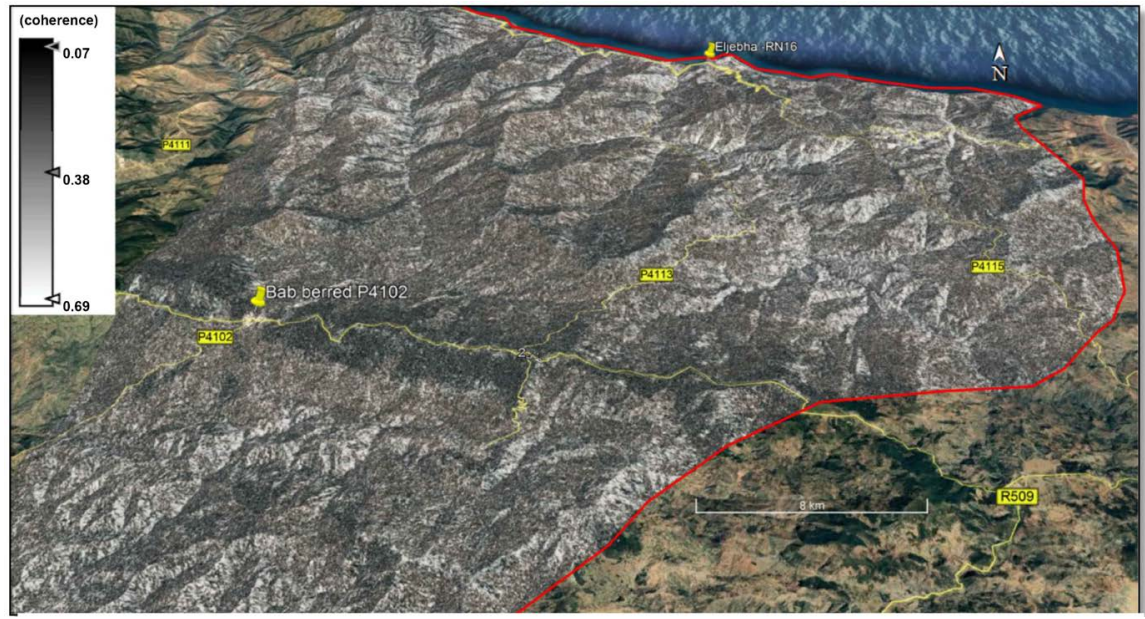

(b)

Figure 5. (a) Coherence Image of June 8/July 26, 2015 obtained from the D-InSAR processing on the area of PK 140 RN16 Eljebha, bab berred. (a) Provincial overview. (b) Coherence Image of June 8/July 26, 2015 obtained from the D-InSAR processing on the area of PK 140 RN16 Eljebha, bab berred, (b) Eljebha and Bab berred area. 


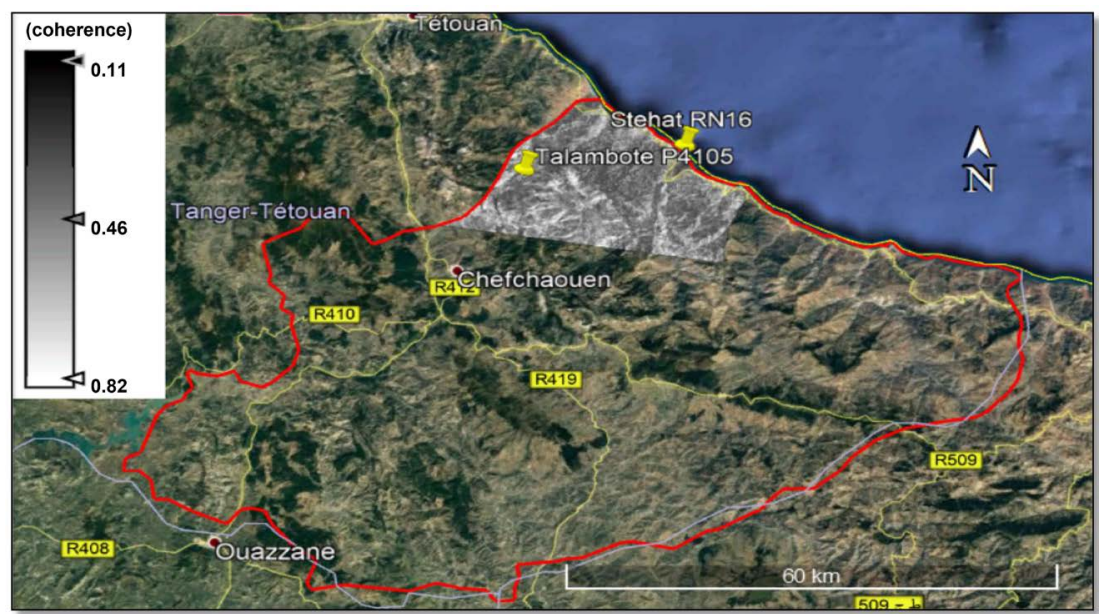

(a)

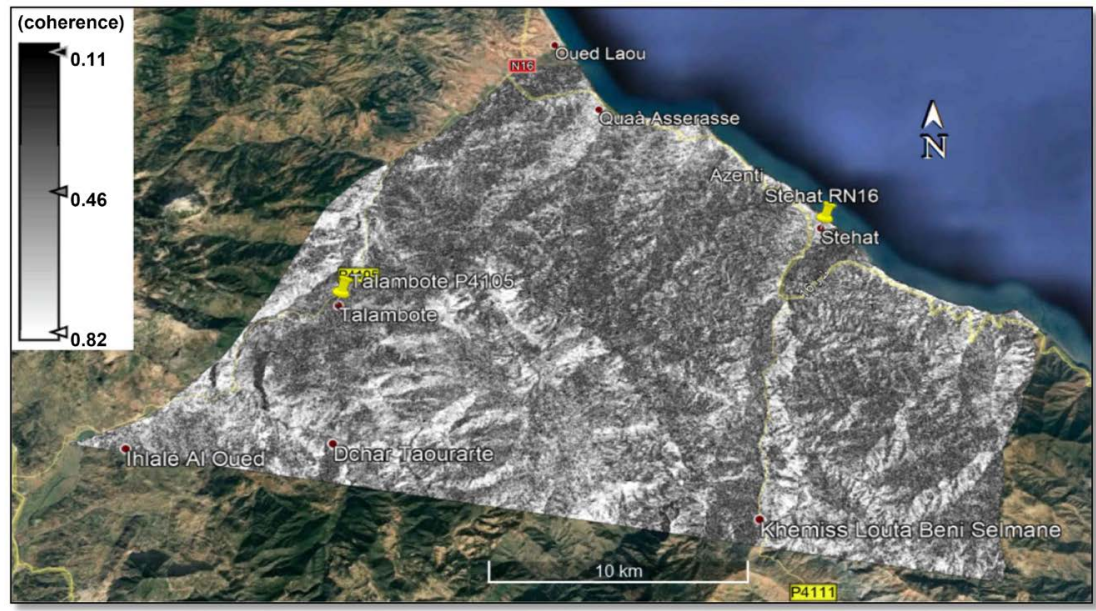

(b)

Figure 6. (a) Coherence Image of 09 June/21 July 2017 obtained from D-InSAR treatment on the RN16 Stehat and Talamobte area. (a) Provincial overview; (b) Coherence Image of 09 June/21 July 2017 obtained from D-InSAR treatment on the RN16 Stehat and Talamobte area. (b) Stehat and Talamobte area.

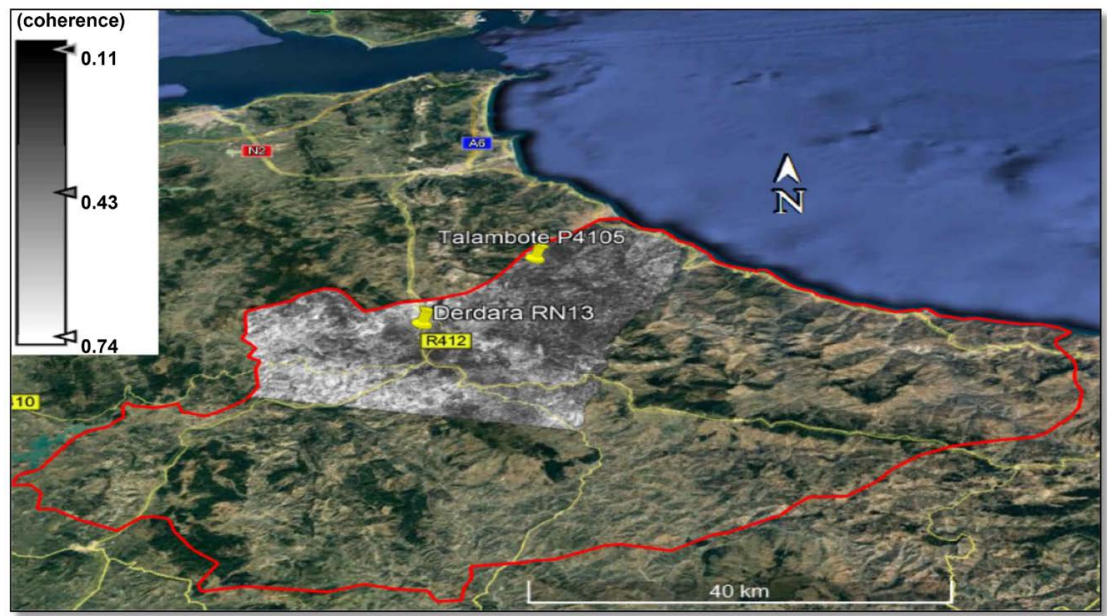

(a) 


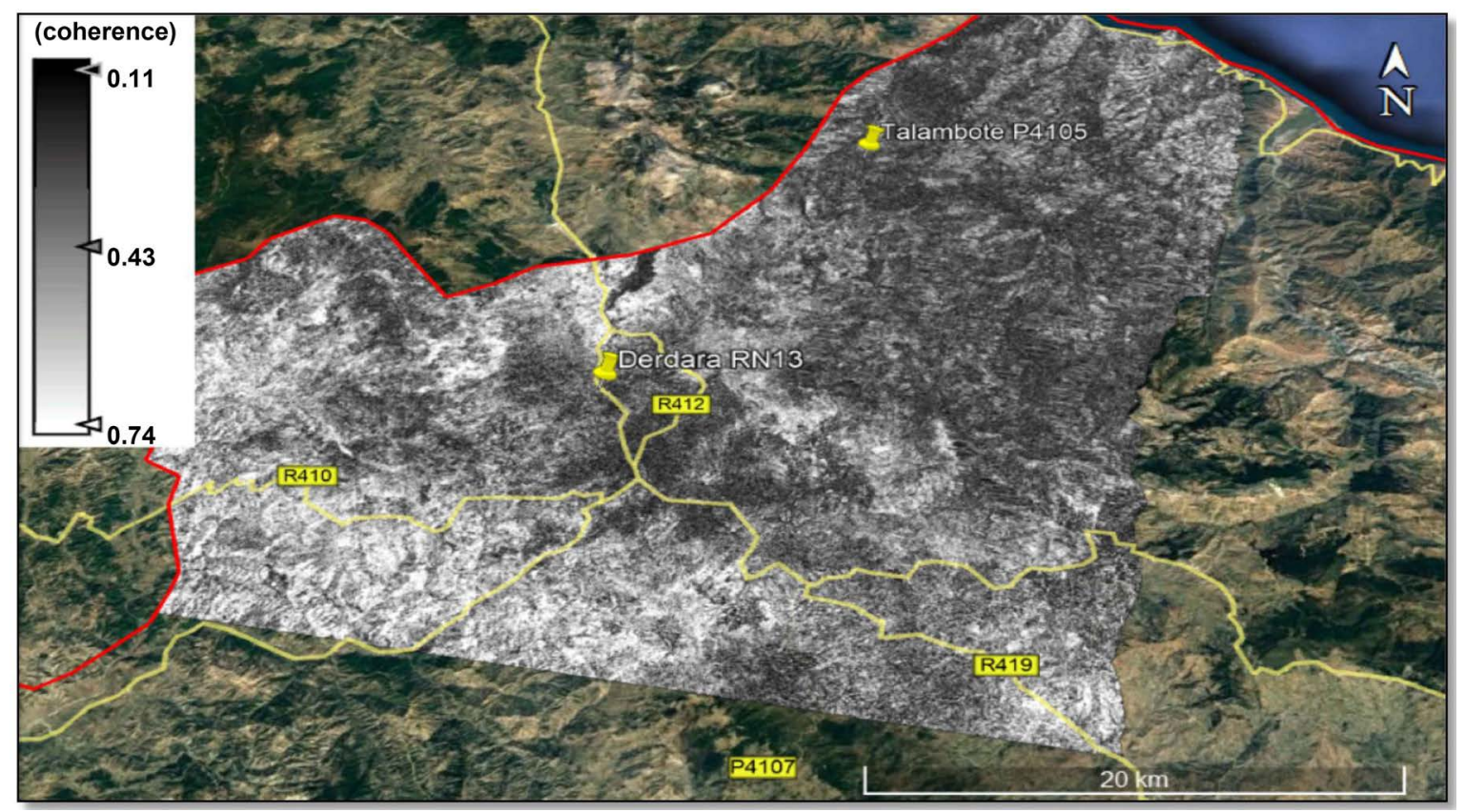

(b)

Figure 7. (a) Coherence Image of 29 July/24 aust 2015 obtained from D-InSAR treatment on the Derdara and Talambote area. (a) Provincial overview; (b) Coherence Image of 29 July/24 aust 2015 obtained from D-InSAR treatment on the Derdara and Talambote area. (b) Derdara and Talambote area.

\subsection{Interferogram Image}

With regard to the generation of Interferograms, three components of three peers the interferometric phase carries a lot of information about the surface deformation (force and direction of movement) and the location of the surface break. Concerning the mapping of landslides from Sentinel-1 data, it has already been reported that the approach is based on the estimation of vertical displacement. The interferometric fringes represent a complete cycle of $2 \pi$. The fringes appear on an interferogram as arbitrary color cycles, each cycle representing half the wavelength of the sensor. The relative ground motion between two points can be calculated by counting the fringes and multiplying them by half the wavelength of the sensor (Meziane et al., 2018).

(Figure 8(a)) shows a differential interferogram generated from Sentinel-1 data, from the 8 June-26 July 2015 couple in Descending orbit, after subtracting all components, namely the atmospheric and residual components and the topography related component, thus the fringes presented show that the ground deformation extends up to 2.75 over the areas of interest (Figure 8(b)). Figure 9(a) shows the descending interferogram of the Stehat and Talambote zone with a time baseline of 51 days it is represented by a color cycle that shows a phase difference of -2.88 to 2.88 (Figure 9 (b)) for the derdara talamobte zone, as shown by the interferogram in (Figure 10(a)), with a time baseline of 25 days which shows the coherence of the zone mean in this period from 29 July to 24 August (Figure 10(b)). 


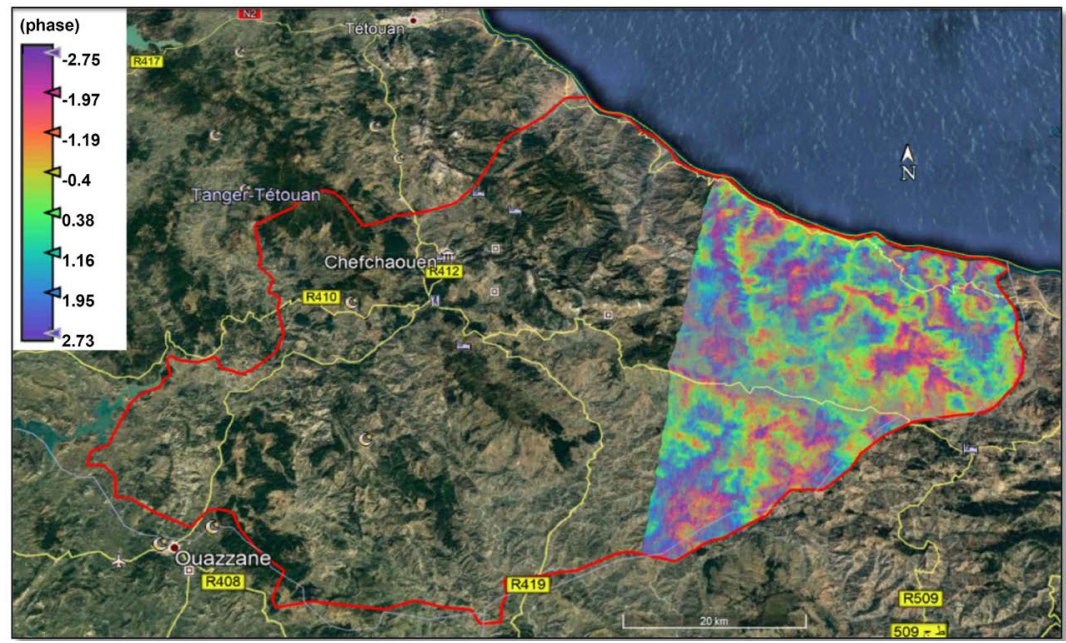

(a)

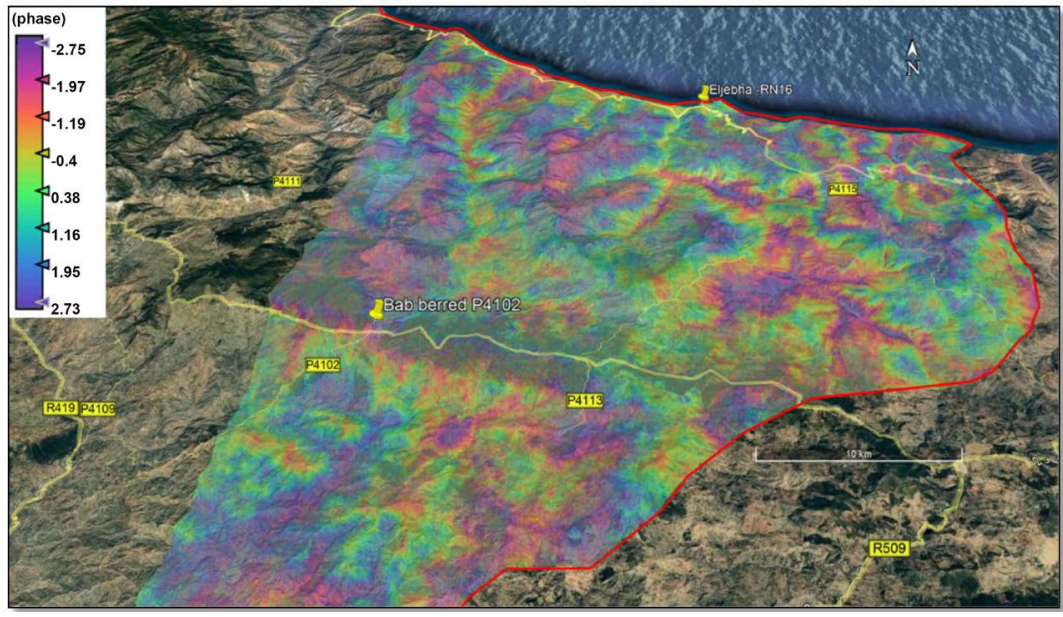

(b)

Figure 8. (a) Interferogram of June 8/July 26, 2015 obtained from the D-InSAR processing on the area of PK 140 RN16 Eljebha Bab berred. (a) Provincial overview; (b) Interferogram of June 8/July 26, 2015 obtained from the D-InSAR processing on the area of PK 140 RN16 Eljebha Bab berred. (b) Eljebha Bab berred area.

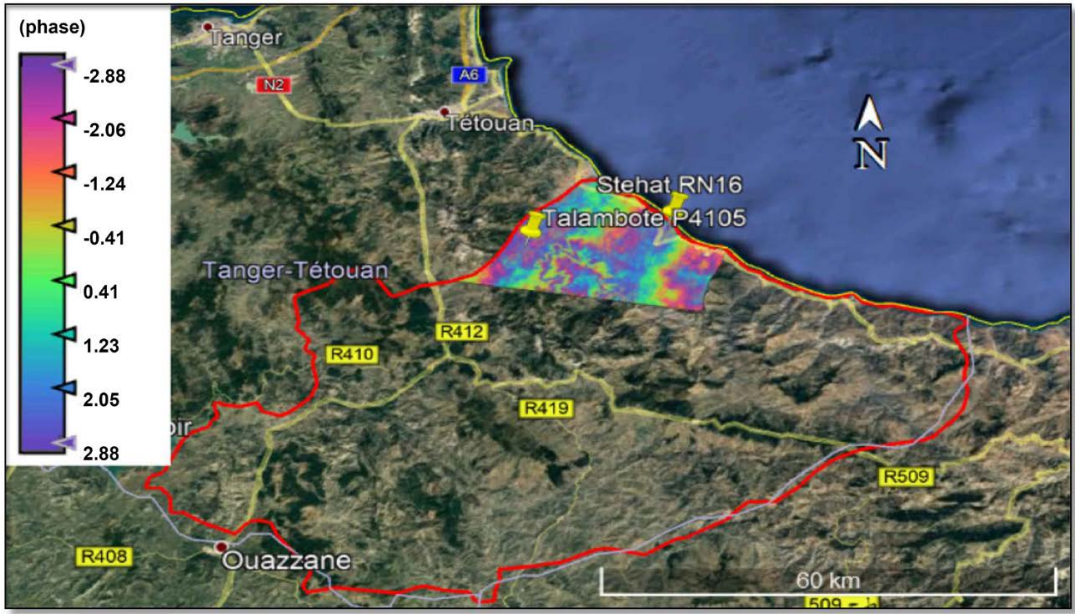

(a) 


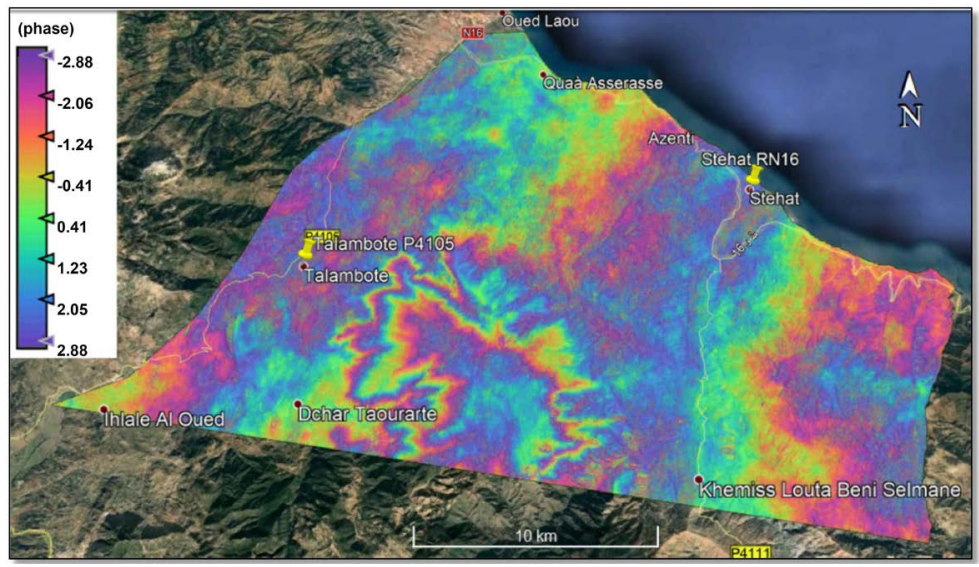

(b)

Figure 9. (a) Interferogram of 09 June/21 July 2017 obtained from D-InSAR treatment on the RN16 Stehat and Talamobte area. (a) Provincial overview; (b) Interferogram of 09 June/21 July 2017 obtained from D-InSAR treatment on the RN16 Stehat and Talamobte area. (b) Stehat and Talamobte area.

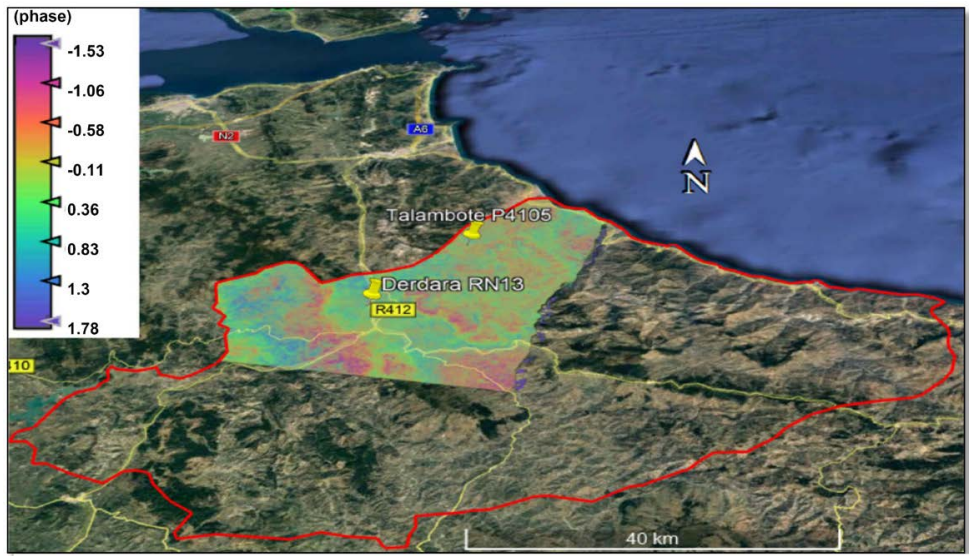

(a)

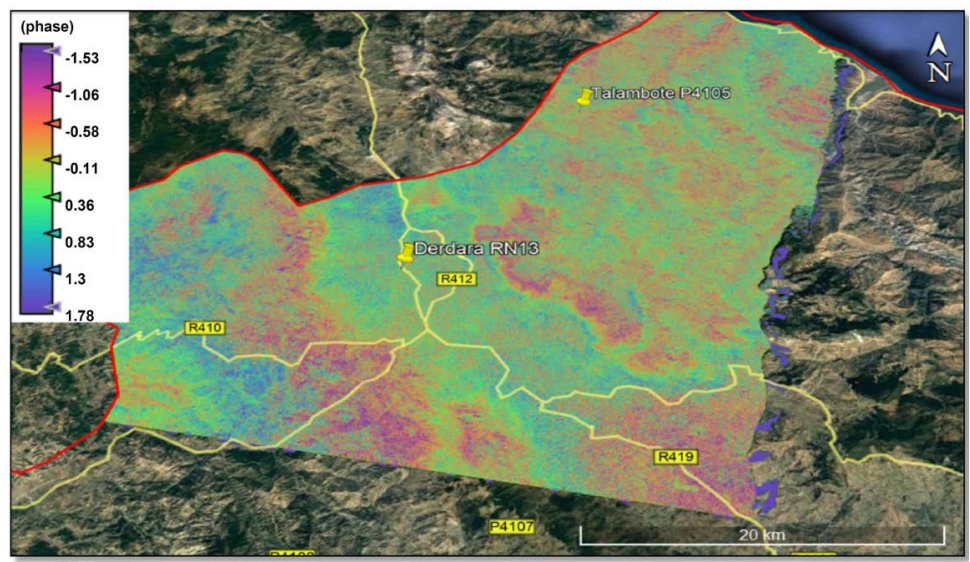

(b)

Figure 10. (a) Interferogram of 29 July/24 aust 2015 obtained from D-InSAR treatment on the Derdara and Talambote area. (a) Provincial overview; (b) Interferogram of $29 \mathrm{Ju}$ ly/24 aust 2015 obtained from D-InSAR treatment on the Derdara and Talambote area. (b) Derdara and Talambote area. 


\subsection{Displacement Map (Figures 11-13)}

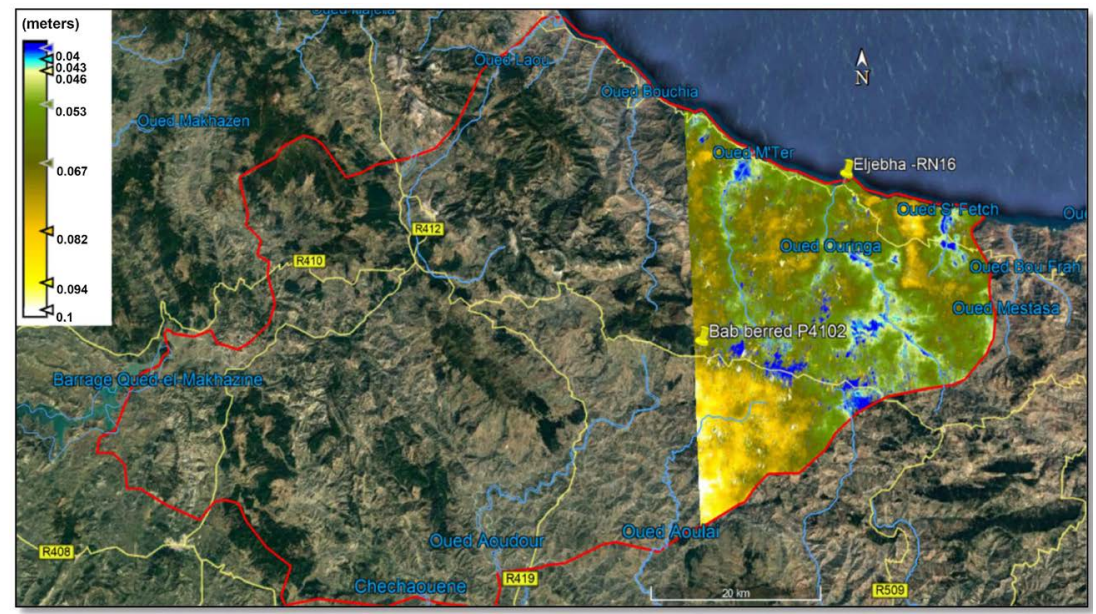

(a)

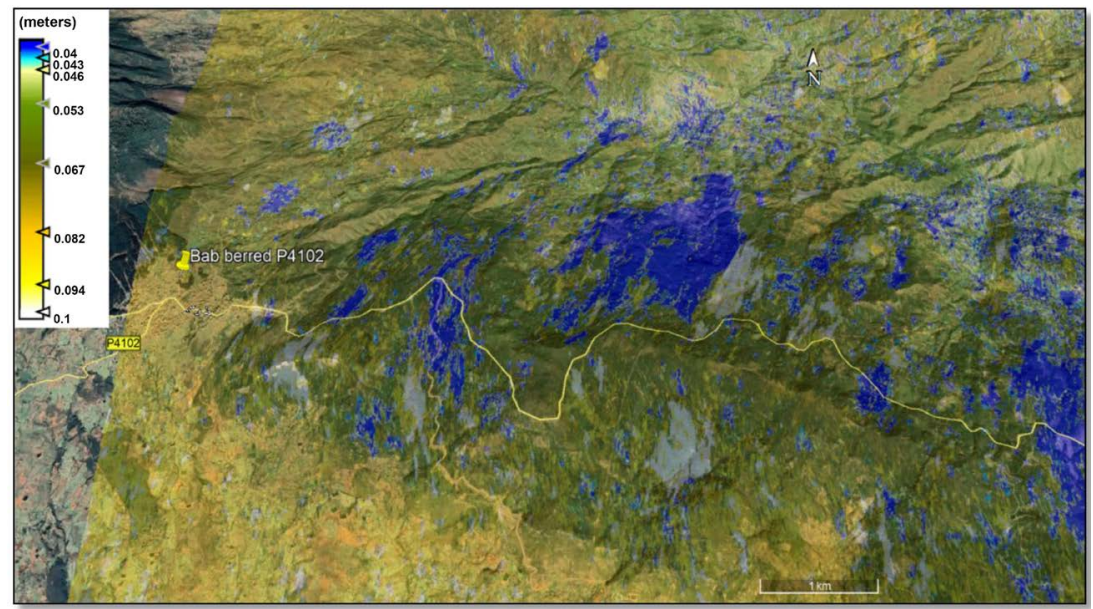

(b)

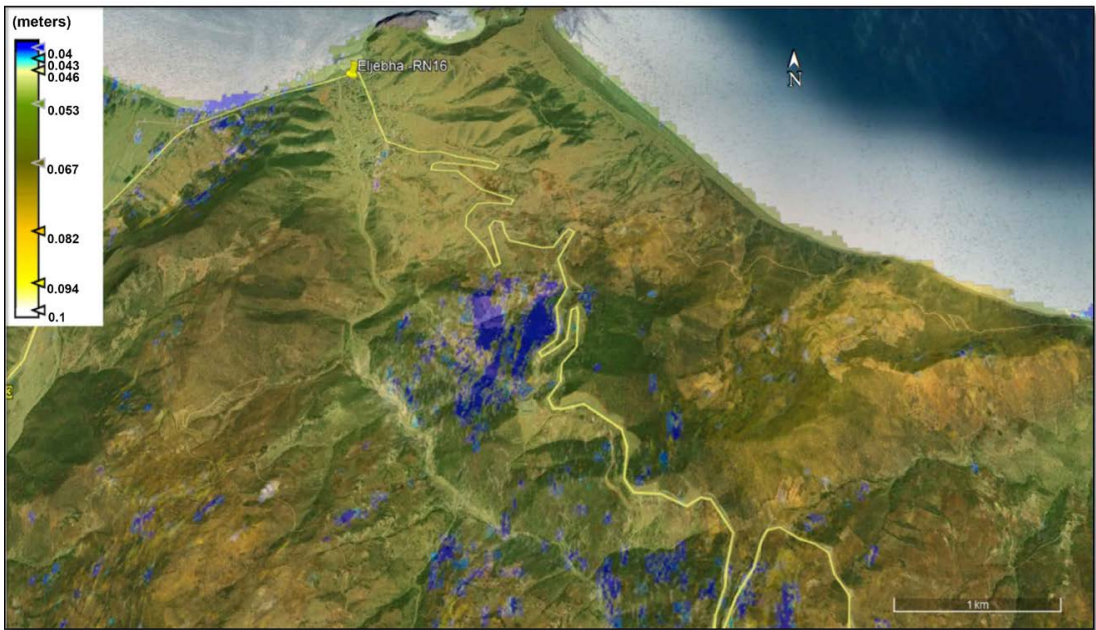

(c)

Figure 11. (a) displacement map of point Eljebha and Bab berred June 8 to July 26, 2015; (b) displacement map of Bab berred area P4102 June 8 to July 26, 2015; (c) displacement map of Eljebha area RN16 June 8 to July 26, 2015. 


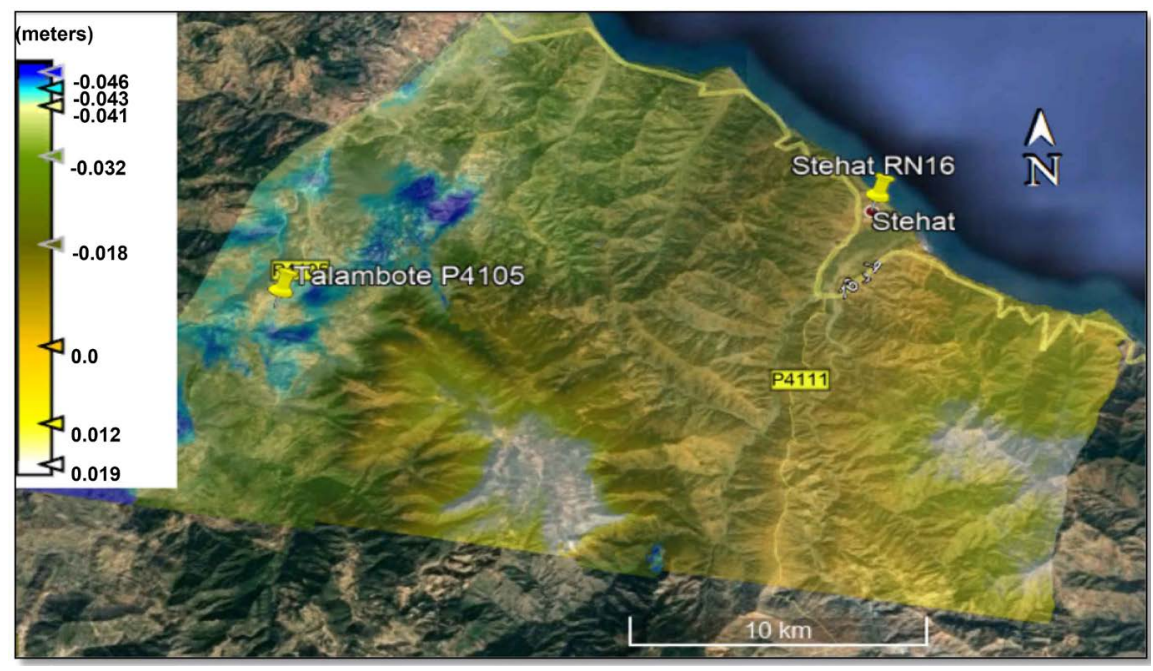

(a)

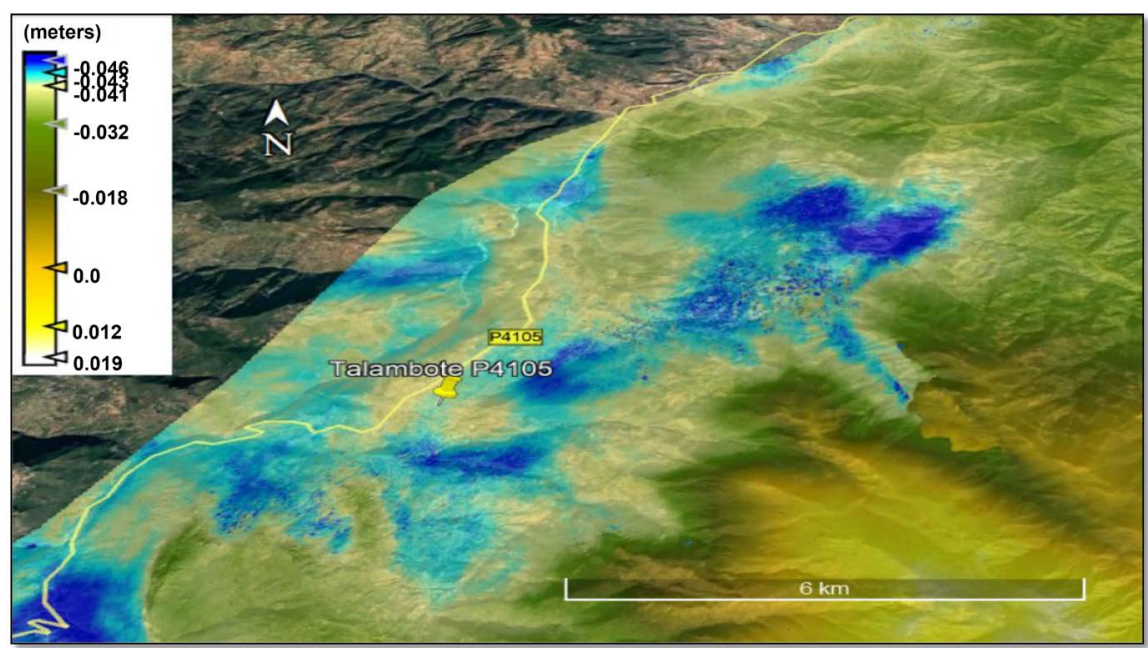

(b)

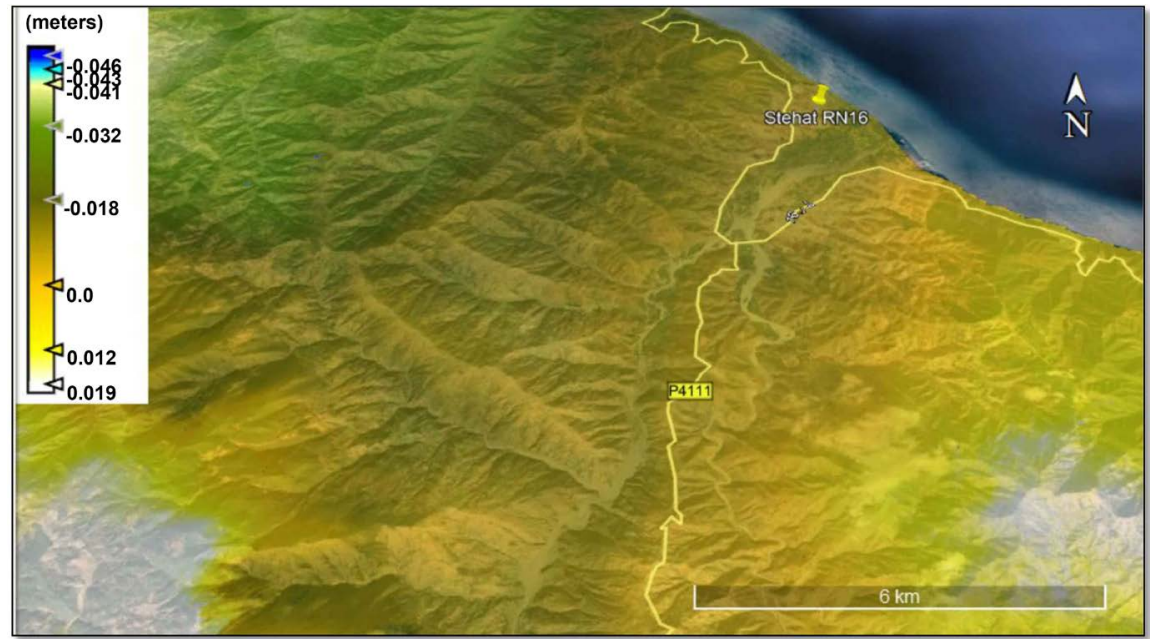

(c)

Figure 12. (a) Displacement map of point RN16 Stehat and talambote June 09 to July, 21 2017; (b) Displacement map of point P4105 talambote June 09 to July, 21 2017; (c) Displacement map of point RN16 Steha June 09 to July, 212017. 


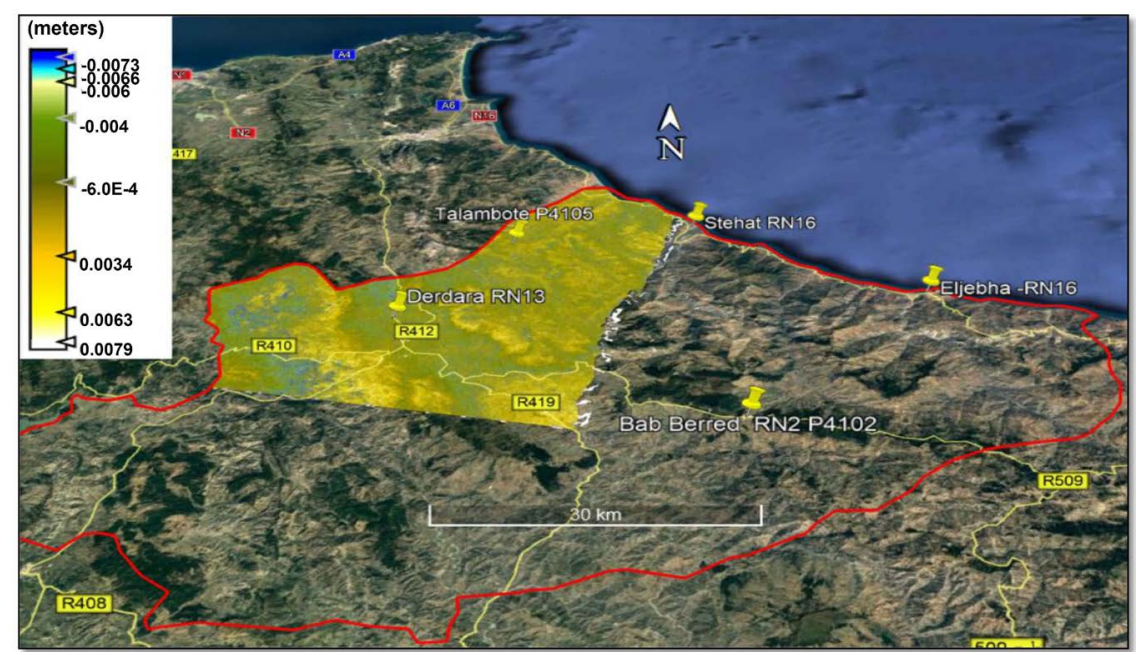

(a)

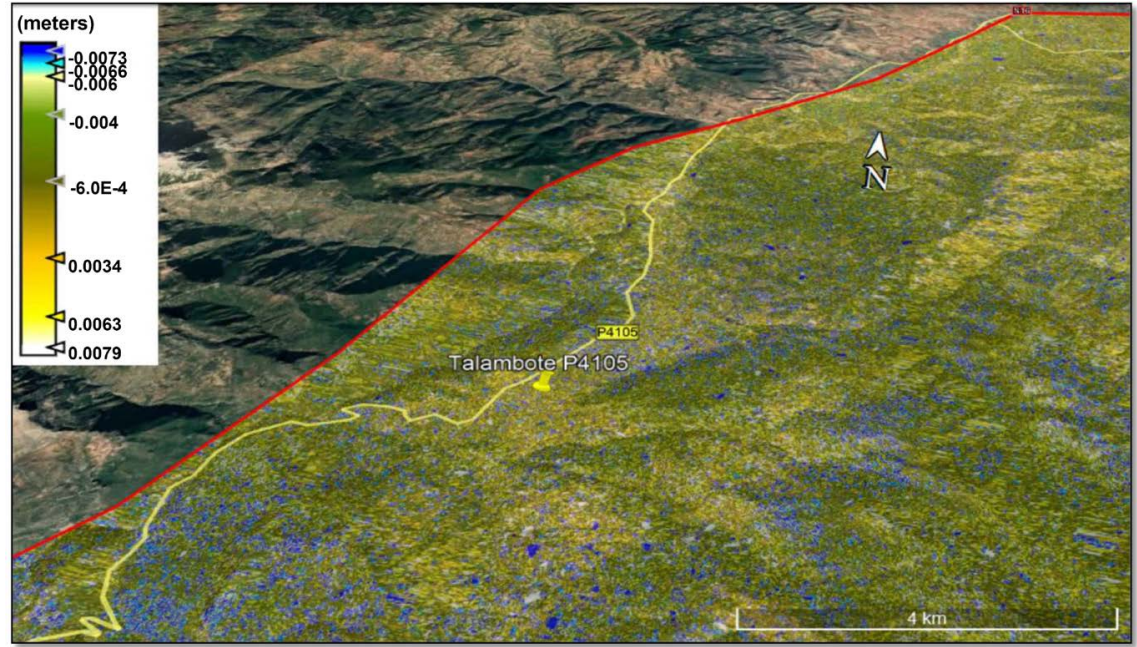

(b)

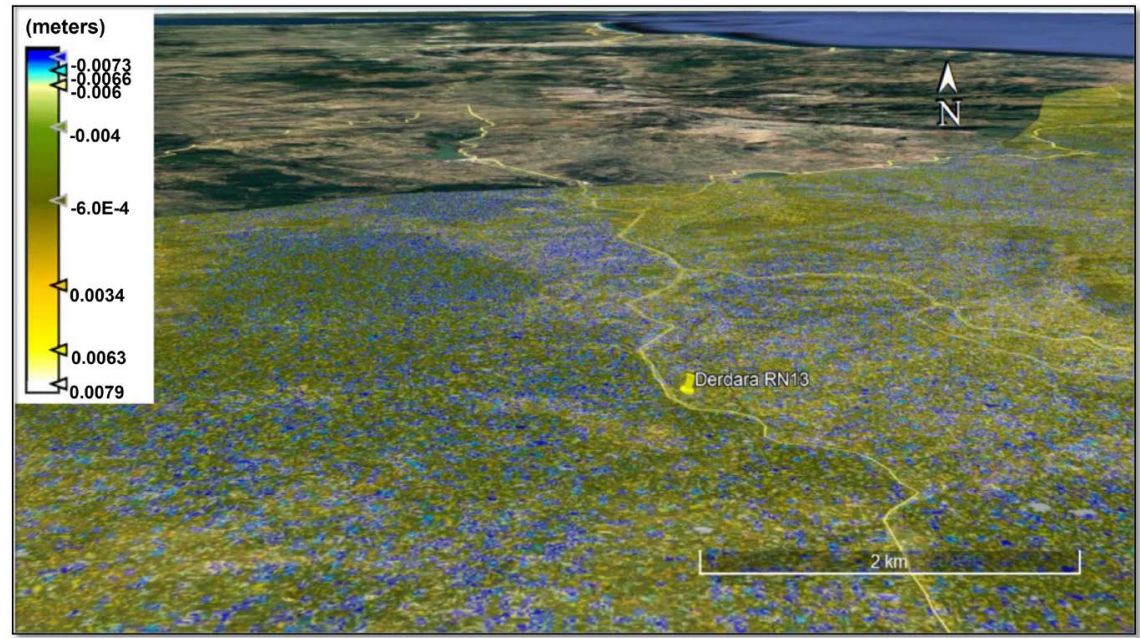

(c)

Figure 13. (a) Displacement map of point RN16 Derdara and talambote from July 29 to August 24, 2015; (b) Displacement map of talambote area from July 29 to August 24, 2015; (c) Displacement map of point RN13 Derdara from July 29 to August 24, 2015. 


\section{Discussion}

The evaluation of the surface deformation caused by the landslide on the Chefchaouen area is carried out through the series of wrapped phase obtained in the fringes which are converted into an unwrapped phase thanks to the unwrapping which is carried out in the platform (SNAPHU), then the displacement maps to were calculated.

The deformation values vary from 0.04 to $0.1 \mathrm{~m}$ in the Bab Berred, Eljebha zone over the period from 8 June, 26 July 2015 (Figures 11(a)-(c) and from 0.019 to $-0.046 \mathrm{~m}$ over the period from 09 June to 21 July 2017 in the Stehat RN16 and Talambote P4105 zone (Figures $12(\mathrm{a})-(\mathrm{c})$ ) and from 0.079 to -0.0073 $\mathrm{m}$ in the Talambote and Derdara zone over the period from 29 July to 24 August 2015 (Figures 13(a)-(c)). and the Figure 14 summarizes the state of deformation of the three deformation maps, we can deduce that the rate of deformation varies according to the temporal baseline and the spatial baseline, in our case in the region of Eljebha on the road RN16 and Bab berred the landslide was very significant on the road of Bab berred, the rate of displacement is around $0.04 \mathrm{~m}$ which confirms the landslide of the date of July 17, 2015 in the area of Bab bered due to major ground movements of the limestone ridge that resulted in the deposition of material obtained during winter and flood periods (Meziane et al., 2018), with regard to the Talamobte and Stehat regions, the strong eastward displacement in the Talambote area, caused by the landslide of June 12, 2017 and finally the landslide in the Derdara area on September 12, 2015 did not cause any major deformations

\section{Conclusion}

The landslide-related ground displacement is analysed in this study by the D-InSAR technique, which has shown its ability to map landslide areas and to validate the landslide points obtained from the direction of roads in mountainous

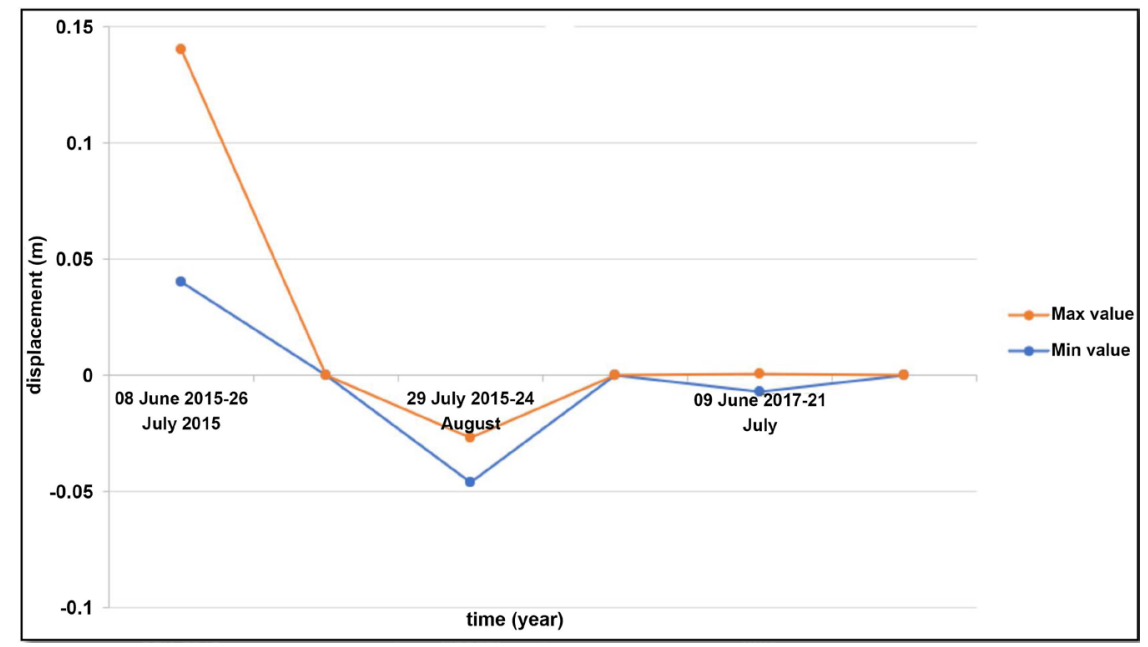

Figure 14. Displacement of the points of interest Eljebha, Bab Berred, Derdara, Talambote according to the years. 
areas with an accuracy of the order of mm/year, using the Sentinel-1 SNAP and SNAPHU toolbox for the unwrapping phase. The application of DInSAR in Northern Morocco is effective, because it allows to freely analyse and map the ground deformation in a remote area (Meziane et al., 2018). This process is useful and gives satisfactory results even if it is based on two SLC images to finally obtain a deformation map visualized in Google Earth; this result may have a positive influence on the adaptation of the D-InSAR method as an approach for monitoring landslides on roads.

In the future works, the PSInSAR technique will be used, and the processing chain of the chronological series of deformations of the same zone will be provided.

\section{Acknowledgements}

This work is supported by the National Center for Scientific and Technological Research (CNRST).

We would like to thank the Road Directorate of Chefcahouen for providing the data.

\section{Conflicts of Interest}

The authors declare no conflicts of interest regarding the publication of this paper.

\section{References}

Bamler, R., \& Hartl, P. (1998). Synthetic Aperture Radar Interferometry. Inverse Problems, 14, R1-R54.

Bell, J. W., Amelung, F., Ferretti, A., Bianchi, M., \&Novali, F. (2008). Permanent Scatterer InSAR Reveals Seasonal and Long-Term Aquifer-System Response to Groundwater Pumping and Artificial Recharge. Water Resources Research, 44, No. 2.

Berardino, P., Fornaro, G., Lanari, R., \& Sansosti, E. (2002). A New Algorithm for Surface Deformation Monitoringbased on Small Baseline Differential SAR Interferograms. IEEE Transactions on Geoscience and Remote Sensing, 40, 2375-2383. https://doi.org/10.1109/TGRS.2002.803792

Bovenga, F., Wasowski, J., Nitti, D. O., Nutricato, R., \& Chiara-dia, M. T. (2012). Using COSMO/Sky Med X-Band and ENVISATC Band SAR Interferometry for Landslides Analysis. Remote Sensing of Environment, 119, 272-285. https://doi.org/10.1016/j.rse.2011.12.013

Cascini, L., Fornaro, G., \& Peduto, D. (2009). Analyse à moyenne échelle des données DInSAR basse résolution dans les zones touchées par les glissements de terrain à mouvement lent. ISPRS Journal of Photogrammetry and Remote Sensing, 64, 598-611. https://doi.org/10.1016/j.isprsjprs.2009.05.003

Catani, F., Farina, P., Moretti, S., Nico, G., \& Strozzi, T. (2005). Sur l'application de l'interférométrie SAR aux études géomorphologiques: Estimation des attributs du relief et des mouvements de masse. Géomorphologie, 66, 119-131. https://doi.org/10.1016/j.geomorph.2004.08.012

Cigna, F., \& Tapete, D. (2012). Rapid Mapping and Deformation Analysis over Cultural 
Heritage and Rural Sites Based on Persistent Scatterer Interferometry. Geophysical Journal International, 2012, $19 \mathrm{p}$.

Colesanti, C., Ferretti, A., Prati, C., \& Rocca, F. (2003). Monitoring Land-Slides and Tectonic Motions with the Permanent Scatterers Technique. Engineering Geology, 68, 3-14. https://doi.org/10.1016/S0013-7952(02)00195-3

Colesanti, C., Le Mouélic, S., Bennani, M., Raucoules, D., Carnec, C., \& Ferretti, A. (2005). Detection of Mining Related Ground Instabilities Using the Permanent Scatterers Technique-A Case Study in the East of France. International Journal of Remote Sensing, 26, 201-207. https://doi.org/10.1080/0143116042000274069

Crosetto, M., Biescas, E., Duro, J., Closa, J., \& Arnaud, A. (2008). Génération de produits SAR interférométriques avancés ERS et Envisat en utilisant la technique du réseau de points stables Photogramme. Engineering Remote Sensing, 74, 443-450.

Farina, P., Colombo, D., Fumagalli, A., Marks, F., \& Moretti, S. (2006). Diffuseurs permanents pour les enquêtes sur les glissements de terrain: Résultats du projet ESA-SLAM. Engineering Geology, 88, 200-217. https://doi.org/10.1016/j.enggeo.2006.09.007

Ferretti, A., Prati, C., \& Rocca, F. (2000). Natural Hazards, 2000; Measuring Subsidence with SAR Interferometry Applications of the Permanent Scatterers Technique. In Proceedings of the 6th International Symposium on Land Subsidence (Vol.2, pp. 67-79). Ravenna, Italy.

Guzzetti, F., Manunta, M., Ardizzone, F., Pepe, A., Cardinali, M., Zeni, G., Reichenbach, P., \& Lanari, R. (2009). Analyse de la déformation du sol détectée à l'aide de la technique SBAS-DInSAR en Ombrie, Italie centrale sPure. Géophysique Appliquée, 166, 1425-1459. https://doi.org/10.1007/978-3-0346-0149-8_13

Heleno, S. I., Oliveira, L. G., Henriques, M. J., Falcão, A. P., Lima, J. N., Cooksley, G., Ferretti, A., Fonseca, A. M., Lobo-Ferreira, J. P., \& Fonseca, J. F. (2011). Persistent Scatterers Interferometry Detects and Measures Ground Subsidence in Lisbon Remote Sens. Environ., 115, 2152-2167.

Hilley, G. E., Bürgmann, R., Ferretti, A., Novali, F., \& Rocca, F. (2004). Dynamics of Slow-Moving Landslides from Permanent Scattereranálisis. Science, 304, 1952-1955. https://doi.org/10.1126/science.1098821

Jung, H., Kim, S., Jung, H., Min, K., \& Won, J. (2007). Satellite Observation of Coal Mining Subsidence by Permanent Scatterer Analysis. Engineering Geology, 92, 1-13. https://doi.org/10.1016/j.enggeo.2007.02.007

Lorenzo, S., Matteo, D., Federico, R., Anna, B., Silvia, B., Nicola, C., \& Michele, C. (2020). Review of Satellite Interferometry for Landslide Detection in Italy. Remote Sensing in Geology, Geomorphology and Hydrology.

Mastere, M. (2011). Susceptibility to Ground Movements in the Province of Chefchaouen (Central Rif, Morocco): Spatial Analysis, Multi-Scale Probabilistic Modelling and Impact on Development and Urban Planning (316 p.). PhD Thesis, Brest: University of Brittany Occidentale.

Meziane, S., Bahi, L., \& Ouadif, L. (2018). Differential Synthetic Aperture Radar Interferometryfor Land Movements Mapping Case of El Jebha (North of Morocco). International Journal of Civil Engineering and Technology, 9, 105-113.

Raucoules, D., Colesanti, C., \& Carnec, C. (2007). Use ofSAR Interferometry for Detecting and Assessing Ground Subsidence. C.R. Geoscience, 339, 289-302.

https://doi.org/10.1016/j.crte.2007.02.002

Stramondo, S., Saroli, M., Tolomei, C., Moro, M., Doumaz, F., Pesci, A., Loddo, F., Baldi, P., \& Boschi, E. (2007). Surface Movements in Bologna (Po Plain-Italy) Detected by 
Multitemporal DInSAR. Remote Sensing of Environment, 110, 304-316.

https://doi.org/10.1016/j.rse.2007.02.023

Tomás, R., Márquez, Y., Lopez-Sanchez, J. M., Delgado, J., Blanco, P., Mallorquí, J. J., Martínez, M., Herrera, M., \& Mulas, J. (2005). Mapping Ground Subsidence Induced by Aquifer Overexploitation Using Advanced Differential SAR Interferometry: Vega Media of the Segura River (SE Spain) Case Study. Remote Sensing of Environment, 98, 269-283. https://doi.org/10.1016/j.rse.2005.08.003

Vallone, P., Giammarinaro, M. S., Crosetto, M., Agudo, M., \& Bi-escas, E. (2008). Ground Motion Phenomena in Caltanissetta (Italy) Investigated by InSAR and Geological Data Integration. Engineering Geology, 98, 144-155.

https://doi.org/10.1016/j.enggeo.2008.02.004

Yerro, A., Corominas, J., Monells, D., \& Mallorqui, J. J. (2014). Analyse de l'évolution des mouvements du sol dans une zone à faible densité urbaine au moyen de la technique DInSAR. Engineering Geology, 170, 52-56.

https://doi.org/10.1016/j.enggeo.2013.12.002 